\title{
Neonatal/infant echocardiography by the non-cardiologist: a personal practice, past, present, and future
}

\author{
J L Katumba-Lunyenya
}

$\Lambda^{\mathrm{n}}$ increasing number of neonatologists and general paediatricians with an interest in neonatology are performing echocardiography on neonates and infants. There have been several articles, a book, and a CD-ROM on the subject by specialists outlining the pros and cons of a generalist developing the skill. ${ }^{1-5}$ However, there has been little or no comment in the paediatric literature by any neonatologists or general paediatricians. This article outlines my personal experience, highlighting possible pitfalls and problems encountered while developing the skill of echocardiography.

\section{WHY SHOULD A NON-CARDIOLOGIST PERFORM ECHOCARDIOGRAPHY?}

My personal view is that echocardiography when properly performed is a very useful ultrasonographic investigation. It can influence the management and outcome of the neonate so much, especially that of the extreme preterm, that I feel that this investigation should be available within 24 hours of requirement. Once weekly or even once fortnightly scanning sessions can no longer be justified. A few paediatricians still believe that if you cannot see, feel, or hear ductal signs, then there is no patent ductus arteriosus (PDA). This is despite a large paediatric literature showing that this is incorrect. ${ }^{126-8}$ It has even been suggested that the absence of a murmur in an infant with a PDA may in fact be "a more sinister sign" haemodynamically. ${ }^{6}$ It is not unusual for regular scanning to detect a haemodynamically significant PDA several days (usually about three) before any signs appear.

Weekly scanning and consequent delayed diagnosis of a PDA may prove costly in terms of morbidity: worse respiratory disease, increased incidence of intraventricular haemorrhage, an increased incidence of necrotising enterocolitis, problems of renal hypoperfusion, and circulatory problems. ${ }^{10}$ Infants who develop a late murmur with or without bounding pulses may in fact have a transient peripheral pulmonary branch stenosis after closure of the duct. This may occur in almost $50 \%$ of cases of $\mathrm{PDA}^{11}$ and blind treatment of infants as though they have a reopened duct may lead to mistakes. Babies may have their fluids restricted, be started on diuretics, or even be put on indomethacin for days before the weekly scan confirms the correct diagnosis. The cause of the bounding pulses in this instance may be high $\mathrm{CO}_{2}$ in an infant with compensated respiratory acidosis secondary to chronic lung disease. The duct does not in fact "wink" and, except rarely in very low birthweight infants, once it closes it does not normally reopen. ${ }^{6}$ In further support of regular scanning of infants with PDA, there is recent evidence from Su et al ${ }^{12}$ that, if PDA flow patterns are followed serially by echocardiography, indomethacin treatment could be stopped before administration of the full course, thus reducing the risk of complications. Most importantly, there was no difference in their series of rate of closure or reopening between infants that received the full course and those that had an abbreviated course.
For the above reasons and others cited below, frequent echocardiography is likely to become the norm on neonatal intensive care units for optimal management, especially of very low birthweight infants. However, there are only about 60 paediatric cardiologists in the United Kingdom, ${ }^{2}$ and other people, preferably neonatologists or paediatricians who care for neonates, will have to learn the skills to provide this facility.

\section{THE PAST}

Mine was the most inauspicious start to the development of the skill of echocardiography, and my story should give encouragement to non-cardiologists like myself who may initially find echocardiography rather daunting.

I was one of a group of paediatricians who attended the very first Oxford paediatric echocardiography course in 1994. I did not use the skill again until 1996 when I was able to acquire a machine for our unit. I then scanned as many normal babies as possible. Familiarisation with the classic scanning views and normal cardiac configuration is essential at the start. I would go as far as to suggest that scanning the obviously clinically abnormal heart should be avoided until one is quite familiar with the structure of the normal heart. One is then in a position to recognise abnormalities. It is important from the outset to be trained to look at all four classical views during each scan. In addition, a long axis view of the arch and descending aorta and a look at the abdominal aorta and inferior vena cava are essential. The practice of most paediatric cardiologists in echocardiographic diagnosis is to identify the position, relation, and connection of each vein and heart chamber to each other, from the inflow to the outflow of the heart following through to the great arteries, identifying abnormalities along the way. This process is known as "sequential chamber localisation"13 and is a logical technique to prevent defects from being missed through the use of short cuts. A machine with colour and pulsed Doppler is highly desirable, and a very good one costs less than $£ 50000$.

I then started weekly attendance at one of the paediatric cardiology clinics at the local tertiary centre. I soon progressed to "taking a look" at infants with heart murmurs from postnatal wards and the neonatal intensive care unit, and also looking for PDAs. If anything abnormal was found, such as a ventricular septal defect, atrial septal defect, or PDA, I would not pronounce a diagnosis, but tell the parents about my suspicions and then arrange for my colleagues at the local tertiary centre to review the case. This was usually within three days, but sometimes on the same day if I was particularly worried. Understandably, a normal scan in the presence of a significant murmur was most worrying. Such cases always prompted referral. Initially, I refused to perform postnatal screening scans for antenatally suspected cardiac lesions or on infants whose parents were worried because of a family history of congenital heart disease. 
Table 1 Cardiac abnormalities diagnosed on our unit by echocardiography

\begin{tabular}{|c|c|}
\hline Type of lesion & Comments \\
\hline VSD (ventricular septal defect) & $\begin{array}{l}\text { Small ones may be missed if one scans too soon after delivery. Interrogation with colour } \\
\text { and pulsed Doppler essential }\end{array}$ \\
\hline ASD (atrial septal defect) & $\begin{array}{l}\text { Subcostal four chamber view is best. Some may be just large patent foramen ovale. } \\
\text { Measurements of size and T- artifactisation }{ }^{14} \text { will help to differentiate. }\end{array}$ \\
\hline AVSD (atrioventicular septal defect) & $\begin{array}{l}\text { Look for the normal offsetting of the inlet valves; the tricuspid valve is usually set more } \\
\text { apically than the mitral valve. }\end{array}$ \\
\hline Fallot's tetralogy & One of these cases was missed in the earlier days and was transferred as a large VSD. \\
\hline \multicolumn{2}{|l|}{ TGA (transposition of the great arteries) } \\
\hline \multicolumn{2}{|l|}{ Pulmonary atresia with intact ventricular septum } \\
\hline Interrupted aortic arch & Four limb oxygen saturations and blood pressures essential \\
\hline Coarctation of the aorta & As above \\
\hline Mild to moderate pulmonary stenosis & Colour and pulsed Doppler are useful. The former to detect and the latter to confirm. \\
\hline Peripheral pulmonary stenosis with Noonan's syndrome & As above \\
\hline Supra-aortic stenosis with William's syndrome & \\
\hline TAPVD (total anomalous pulmonary venous drainage) & $\begin{array}{l}\text { One case was misdiagnosed as another cyanotic lesion because I was in a hurry. Give } \\
\text { yourself time. }\end{array}$ \\
\hline Transient peripheral pulmonary stenosis & $\begin{array}{l}\text { Usually postductal closure and often misdiagnosed as a "winking duct". }{ }^{6} \text { This is a } \\
\text { physiological phenomenon. }\end{array}$ \\
\hline Atrial flutter & Very impressive echo pictures. Atria look as if they are being oscillated. \\
\hline
\end{tabular}

It is of paramount importance that scanning should not be stopped when a lesion is found, because an associated lesion could be missed. This happened to me in the early days when the excitement of finding a ventricular septal defect in a pink newborn infant with a murmur stopped me from looking any further and so I missed the obvious overlying aorta and all the other features of a Fallot's tetralogy. I was most annoyed with myself when the paediatric cardiologist rang later that day to tell me the diagnosis, although he was very gracious and encouraging. The support, supervision, encouragement, and lack of pomposity of the local tertiary centre are absolute requirements for success for all aspiring echocardiographers.

There is a feeling of surprise when one actually starts to correctly diagnose various congenital heart problems. It is at this stage, however, that one's limitations should be recognised. It is essential that a cardiologist assesses the infant at the earliest possible opportunity.

During this period, access to good reading material is highly desirable, and there are several books and an interactive CD-ROM on the market. ${ }^{31415}$ Polishing up on theoretical knowledge is highly recommended.

\section{THE PRESENT}

After about 18 months of scanning, to my amazement, the tertiary centre pronounced that they considered me competent enough to "go solo". This paradoxically made me scan even more thoroughly and carefully because I was terrified of missing something and therefore still maintained a very low threshold for referral. The tertiary centre to their credit put up with my insecurity without complaint until I started to share their conviction about my competence! This belief in myself developed very gradually after completion of quite a significant portfolio of successful diagnoses. One is likely to come across more scepticism from local colleagues than from experts because of the myth surrounding echocardiography. The belief of the former in your ability is more difficult to win.

Formal accreditation after a period of training and supervision may help to build personal confidence and gain support from colleagues. There are also medicolegal implications associated with verification of training and maintenance of skills.

Once colleague confidence is gained, you have to firmly refuse inappropriate referrals. Examples of these are: general practitioner referrals to other colleagues being redirected to you without proper clinical assessment; heart murmurs picked up by senior house officers during routine neonatal checks being listed for an echocardiographic examination without assessment by a more senior paediatrician and before a detailed physical examination including four limb oxygen saturations and blood pressures.

After another six months of scanning I was invited to teach on the Oxford echocardiography course and given responsibility for teaching neonatal echocardiography. I still try as often as possible to sit in with a paediatric cardiologist on clinic days either during outreach clinics or at the tertiary centre.

Echocardiography has substantially improved the care of the neonate with a PDA or hypotension, the cyanosed infant with or without persistent pulmonary hypertension of the newborn (PPHN), the dysmorphic infant, and the infant with heart murmur on our unit. The infant with PPHN must be scanned very carefully paying particular attention to the direction of atrial shunting, pulmonary venous flow, and absence of a pulmonary venous confluence, as this condition closely resembles total anomalous pulmonary venous drainage (TAPVD). ${ }^{16}$ The latter condition can quite easily be missed $^{17}$; I have missed one myself by making the cardinal mistake of scanning too quickly. On that occasion I was asked to see an infant at my local hospital with a probable heart problem when I was already late for another appointment. I decided to take a quick look and did not give myself adequate time to scan properly and missed the TAPVD. In the event, I had not been happy with my diagnosis as everything did not quite add up, and so I sought urgent transfer to a cardiology unit. I comfort myself with the fact that several experienced cardiologists have missed TAPVD. The important point here is that the patient was transferred urgently because my diagnosis did not make complete sense. If in any doubt, an urgent cardiological opinion should always be sought.

Assessment of hypotensive neonates by echocardiography is going to become a major part of their management because most are in fact not hypovolaemic ${ }^{318-21}$ but instead have problems related to myocardial contractility or ductal patency. Most do not therefore need infusion of volume expanders, which are in fact potentially dangerous, ${ }^{22}{ }^{23}$ but treatment with inotropes or therapeutic ductal closure. ${ }^{318} 19212425$ Reliable assessment of ventricular function is a skill that, although a little more difficult to master, is achievable with proper instruction at a more advanced echocardiography course for non-cardiologists.

The positioning of central lines can be easily confirmed at the bedside by echocardiography, and an infant that suffers a catastrophic unexplained deterioration can be quickly scanned for the rare but dreaded complication of cardiac tamponade secondary to extravasated parenteral fluid. ${ }^{3}$ This may be life saving, as previously this complication has been associated with high mortality. 
All specialist paediatric registrars (SPRs) on our unit are encouraged to attend an echocardiography course and are then given further hands on experience during the neonatal part of their tenure at our hospital. Most learn to recognise a PDA, although the decision to treat with indomethacin is made by a more senior paediatrician. Some SPRs have left with quite an impressive portfolio of cardiac lesions on video.

Echocardiography has become such a vital part of our armamentarium in the management of the extreme preterm infant that it has become difficult to imagine how we ever managed without it. Table 1 shows examples of cardiac abnormalities diagnosed on our unit by echocardiography.

\section{THE FUTURE}

The future lies in telemedicine with establishment of links between peripheral hospitals and tertiary centres. ${ }^{26}$ This will not only enhance training in and maintaining the skill of echocardiography, but will also improve management by allowing ready consultation. It will also mean fewer unnecessary transfers to tertiary centres for assessment of congenital heart disease. This will have several benefits: ease of clinical management of the infant ${ }^{27}$; financial savings; the unquantifiable parameter of convenience for the family. The person actually performing the scan need not be very experienced, as instructions on where to point the head to obtain the necessary views can be given over the telelink. There is enough evidence from both sides of the Atlantic ${ }^{27}{ }^{28}$ that the study of pictures transmitted using this innovative and relatively cheap facility can result in a high degree of accuracy of diagnosis. We are in the process of installing it on our unit funded by a charity.

It is my belief that echocardiography is going to become an essential tool for the management of the sick neonate and that neonatologists should be encouraged to learn the skill. My story should give encouragement to all those who want to develop the skill but are, like me at the beginning, a little apprehensive.

\section{ACKNOWLEDGEMENTS}

I would like to thank the Department of Paediatric Cardiology at Oxford for their support and encouragement. Our neonatal intensive care unit is grateful to Mrs Sally Stafford and Mrs Pat Roberts, cofounders of the charitable body Telemed, for funding our telemedicine project. I am indebted to Drs Nick Archer, Mike Burch, and Kevin Ives for their advice and constructive criticism of the manuscript.

Author's affiliations

J L Katumba-Lunyenya, Neonatal Intensive Care Unit, Milton Keynes Hospital NHS Trust, Standing Way, Eaglestone, Milton Keynes, Bucks MK6 5LD, UK Correspondence to: Dr Katumba;

Jasper.Katumba@MKG-TR.anglox.nhs.uk

Accepted 28 August 2001

\section{REFERENCES}

1 Rutter N. Echocardiography for the neonatologist. Current Paediatrics 1999:9:128-31.
2 Skinner JR. Echocardiography on the neonatal unit: a job for the neonatologist or the cardiologist? Arch Dis Child Fetal Neonatal Ed 1998;78:F401-2.

3 Skinner J, Alverson D, Hunter S. Echocardiography for the neonatologist. Edinburgh: Churchill-Livingstone, 2000.

4 Evans N, Malcolm G. Practical echocardiography for the neonatologist. Part 1. Normal 2D imaging and Doppler: an interactive multimedia CD-ROM. Sydney: Royal Prince Alfred Hospital, 2000.

5 Penny DJ, Shekerdemian LS. Management of the neonate with symptomatic congenital heart disease. Arch Dis Child Fetal Neonatal Ed 2001;84:F141-5.

6 Skinner J. Diagnosis of patent ductus arteriosus. Semin Neonatol 2001;6:49-61.

7 Evans N. Diagnosis of the patent ductus arteriosus in the preterm newborn. Arch Dis Child 1993;68:58-61

8 Evans N. The neonate and ductus arteriosus: importance, diagnosis, and practical management. Current Paediatrics 1995;5:114-17.

9 Skinner JR, Hunter S, Hey EN. Cardiorespiratory collapse and the silent ductus. Klin Padiatr 1991;203:52.

10 Knight BD. The treatment of patent ductus arteriosus in preterm infants. A review of randomized trials. Semin Neonatol $2001 ; 6: 63-73$.

11 Arlettaz R, Archer N, Wilkinson AR. Closure of the ductus arteriosus and development of the pulmonary branch stenosis in babies less than 32 weeks of gestation. Arch Dis Child Fetal Neonatal Ed 2000;85:in press.

12 Su B-H, Peng C-T, Tsai C-H. Echocardiographic flow pattern of patent ductus arteriosus: a guide to indomethacin treatment in premature infants. Arch Dis Child Fetal Neonatal Ed 1999;81:197-200.

13 Skinner J, Alverson D, Hunter S. Echocardiography for the neonatologist. Edinburgh: Churchill-Livingstone, 2000:174-9.

14 Snider A, Serwer G, Ritter S. Echocardiography in paediatric heart disease. St Louis: Mosby, 1997.

15 Archer N, Burch M. Paediatric cardiology: an introduction. London: Chapman and Hall, 1998.

16 Evans N. Echocardiographic assessment of the newborn infant with suspected persistent pulmonary hypertension. Semin Neonatol 1997;2:37-48.

17 Linday LA, Ehlers KH, O'Loughlin JE, et al. Noninvasive diagnosis of persistent fetal circulation versus congenital heart defects. Am J Cardiol 1983;52:847-51

18 Kluckow M, Evans N. Low systemic blood flow in the preterm infant. Semin Neonatol 2001;6:75-84

19 Seri I. Circulatory support of the sick preterm infant. Semin Neonatol $2001 ; 6: 85-95$.

20 Barr PA, Bailey PE, Sumners J, et al. Relation between arterial blood pressure and blood volume and effect of infused albumin in sick preterm infants. Paediatrics 1977;60:282-9.

21 Gill AB, Weindling AM. Randomized controlled trial of plasma protein fraction versus dopamine in hypotensive very low birth weight infants. Arch Dis Child Fetal Neonatal Ed 1993;69:284-87.

22 Seri I, Evans J. Acid base, fluid and electrolyte management in the newborn. In: Taeusch HW, Ballard RA, Avery ME, eds. Diseases of the newborn. 7th ed. Philadelphia: WB Saunders Co, 1998:372-93.

23 Van Marter LJ, Leviton A, Allred EN, et al. Hydration during the first few days of life and the risk of bronchopulmonary dyspalsia in low birth weight infants. J Paediatr 1990;116:942-9.

24 Seri I. Cardiovascular, renal, and endocrine actions of dopamine in neonates and children. J Paediatr 1995;126:333-44.

25 Seri I, Tulassay T, Kiszel J, et al. Cardiovascular response to dopamine in hypotensive preterm infants with severe hyaline membrane disease. Eur J Paediatr 1984;142:3-9.

26 Casey FA. Telemedicine in paediatric cardiology. Arch Dis Child 1999:80:497-9.

27 Randolph GR, Hagler DJ, Khandheria BK, et al. Remote telemedical interpretation of neonatal echocardiograms: impact on clinical management in a primary care setting. J Am Coll Cardiol 1999:34:241-5.

28 Mulholland HC, Casey F, Brown D, et al. Application of a low cost telemedicine link to the diagnosis of congenital heart defects by remote consultation. Heart 1999;82:217-21. 